\title{
Percutaneous transforaminal lumbar endoscopic discectomy: An appropriate outpatient procedure for lumbar disc pathologies in a high output tertiary care centre
}

\author{
Jay Prakash V. Modi ${ }^{1}$, Bhavya B Shah ${ }^{2}$, Harshil R Patel ${ }^{3}$, Meet S Mehta ${ }^{4, *}$, Dhimant V Patel ${ }^{5}$ \\ ${ }^{1} \mathrm{HOD},{ }^{2}$ Senior Resident, ${ }^{3}$ Fellow Spine, ${ }^{4} 3^{\text {rd }}$ Year Resident, ${ }^{5}{ }^{\text {nd }}$ Year Resident, Dept. of Orthopaedics, B.J. Medical College, \\ Ahmedabad, Gujarat, India \\ *Corresponding Author: Meet S Mehta \\ Email: meetmehta191@gmail.com
}

\begin{abstract}
Introduction: A very common problem that we come across is that of lower backache in middle aged and elderly, in which disc prolapse is far more prevalent in the population than realised. However, radicular steps like spine surgery is a frightening concept for most. In our world, where technology has undergone such advances, offering a concept like day care spine surgery that too under local anaesthesia for relief of radicular pain, will be a welcome breath. This treatment option not only works faster than epidural injection or oral pain relievers, but also is a more permanent mode of treatment in a tertiary care centre where patient load is a big issue.

Objectives: The aim of this study was to determine the success and surgical outcome of percutaneous transforaminal lumbar endoscopic discectomy on patients with disc prolapse and benefit to the hospital due to rapid turnover of patients.

Material and Methods: Total 20 patients were followed and reviewed in Civil Hospital, Ahmedabad from between July to December 2016. Visual Analog Scale (VAS) was used to assess relief from pain and radiculopathy and Macnab's criteria to know the patient satisfaction.

Results: At the end of 6 weeks, mean post-operative VAS was 3 as compared to pre-operative 8.8 Macnab's criteria gave excellent and good results in $80 \%$ individuals. Mean hospital stay was 1.2 days with no complications like dural tear or infection. One patient underwent open discectomy.

Conclusion: Transforaminal lumbar endoscopic discectomy is a novel technique for most of the government tertiary care centres with many patients but lacking advanced technology. Inspite of having a steep learning curve and high one time cost of instruments, it could become gold standard as it relieves symptoms immediately reducing surgical and anaesthetic complications. It being a day care procedure results in rapid turnover of patients.
\end{abstract}

Keywords: Transforaminal, Lumbar discectomy, Percutaneous endoscopic.

\section{Introduction}

Percutaneous transfacetal transforaminal endoscopic discectomy is a novel minimally invasive approach to address disc herniations. This technique allows a trend to start day care spine surgery in which procedures can be performed under local anaesthesia with mild sedation and patient can walk out of operation theatre immediately with a drastic decrease in pre-operative symptoms. Our purpose is to determine the surgical outcome of percutaneous transforaminal lumbar endoscopic discectomy.

\section{Materials and Methods}

Prospective study of 20 patients operated in Civil hospital, Ahmedabad from in between July -2016 to December -2016.

Patients selected were followed for a period of six months.

\section{Inclusion Criteria}

1. Symptoms and signs of lumbar monoradiculopathy, dysesthesias and lower limb weakness.

2. Radiologic evidence of disc herniation, including contained and extruded disc as well as disc bulge.

3. Individuals conservatively managed for at least 12 weeks.
4. Skeletally mature and medically fit individual.

\section{Exclusion Criteria}

1. Severe central canal stenosis

2. Instability on flexion-extension view

Patients returned for clinical follow-up at 6 weeks and later at 6 months. Follow up rate was $100 \%$. Preoperatively lumbar spine AP and lateral-flexion and extension views and MRI was done.

VAS (Visual Analogue Scale) was used for clinical recovery. VAS ranges from "0" (no pain) to "10" (severe pain). In case of incomplete clinical recovery (vas score more than 4) repeat MRI was done. Macnab criteria was also used to assess the satisfaction of patients in terms of their ability to return back to their work. Results were classified as excellent if the patient had no pain and no limitation of activities, good if the patient reported occasional pain or dysesthesias without any restrictions of daily activities, and did not need any pain medication, fair if their pain improved somewhat but they continued to need pain medication and Poor, if their function worsened or they needed additional surgery to address their symptoms.

Procedure: ${ }^{1}$ Patients were pre-operatively counselled and briefly explained about the procedure. Written consents were taken. We used prone position. Preoperatively, all patients received $1.5 \mathrm{~g}$ of ceftriaxone 
and sulbactam intravenously as antibiotic prophylaxis. $2 \%$ lignocaine was used as local anaesthetic with standard 20 gauge needle. Facetal instillation was done using specialized spinal arthroscopic needle. Total dose was calculated on basis of weight as suggested by the anaesthetist.

Careful aspiration was done before instillation of drug to avoid blood or CSF injection.

Operating room set-up Instruments/Materials Required Radiolucent table. Intraoperative fluoroscopy (C-arm). Wilson frame. TV monitor. Safety drills (from 4 to $9 \mathrm{~mm}$ ). Endoscope with working channel. Guidewires and Tom Shidi needle (max Morespine, Unterfohring, Germany).

Step 1: Marking: K-wire and c-arm are used to mark the level of incision. In AP VIEW, a line is drawn from superior articular facet of lower level to middle of superior endplate of lower level. In dead lateral view, line is drawn from facet joint at the concerned level to the pathologic disc space. Intersection of above lines is the usual entry point. Trajectory can be known from the lines drawn with skin markers.

Step 2: Incision: The skin incision is marked $12 \mathrm{~cm}^{4}$ from the midline at level L5-S1. When operating on level L4-L5 or levels L3-L4 and L2-L3, the incision should be marked 10 and $8 \mathrm{~cm}$ from the midline, respectively. ${ }^{1}$
Step 3: Introduction of Guidewire: After infiltration of the skin with $2-3 \mathrm{~mL}$ lidocaine $2 \%$, an $18-\mathrm{G}$ needle is introduced anaesthetizing the trajectory with 8-10 $\mathrm{mL}$ lidocaine $2 \%$. Angles to be set as per drawn trajectory. When the SAP is reached 2-3 mL lidocaine $1 \%$ is used to anaesthetize the facet joint. However, since too much lidocaine can easily anaesthetize the nerve root. As result, direct nerve root feedback from the patient will be lost. If there is radicular pain, then another trajectory must be used. In case of failure of new trajectory, one must proceed towards open discectomy, the entry for which can be made with help of Jamshidi needle. After this, the stillete will be removed to introduce the guide wire. A series of cannulated rods will then be inserted at the site to widen the opening to about $8 \mathrm{~mm}$.

Step 4: Introduction of the Tom Shidi Needle: The Tom Shidi (cannulated) needle is placed over the wire to the SAP which is then removed and Tom Shidi needle is advanced towards the top of the SAP. The needle is then carefully hammered downwards towards the Kambin's zone ${ }^{2,3}$ until the medial pedicle line is reached. A break in the cortex will be heard by a change of the hammering sound. After this a blunt needle tip is introduced in the spinal canal toward the disk herniation. The guidewire is then used to replace the Tom Shidi needle.

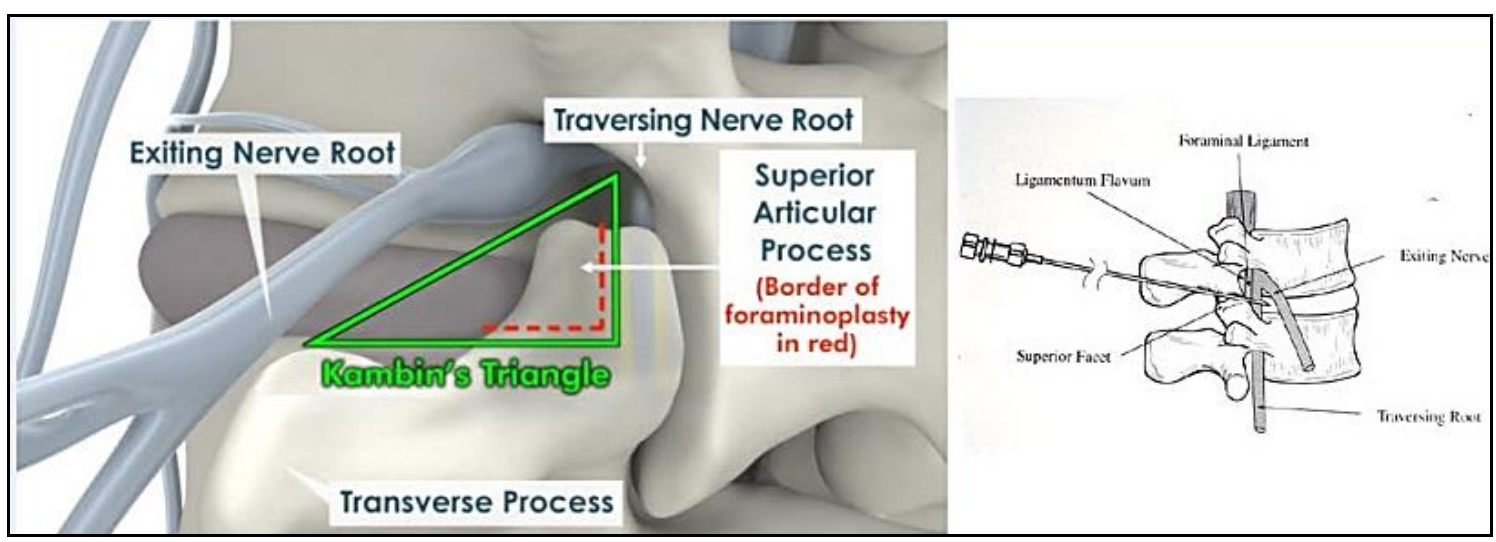

Fig. 1: Kambin's triangle ${ }^{2,3}$

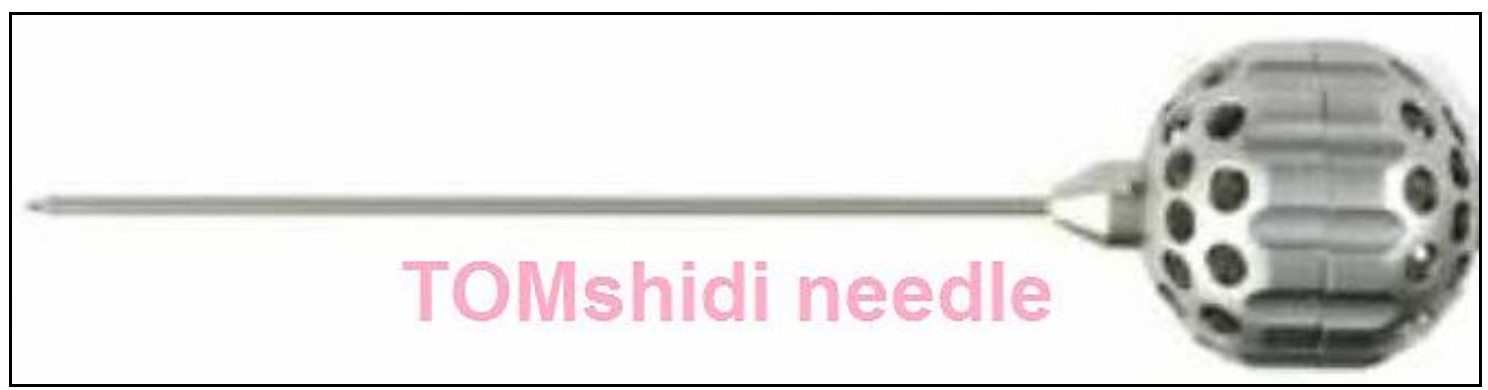

Fig. 2: Tomshidi needle 

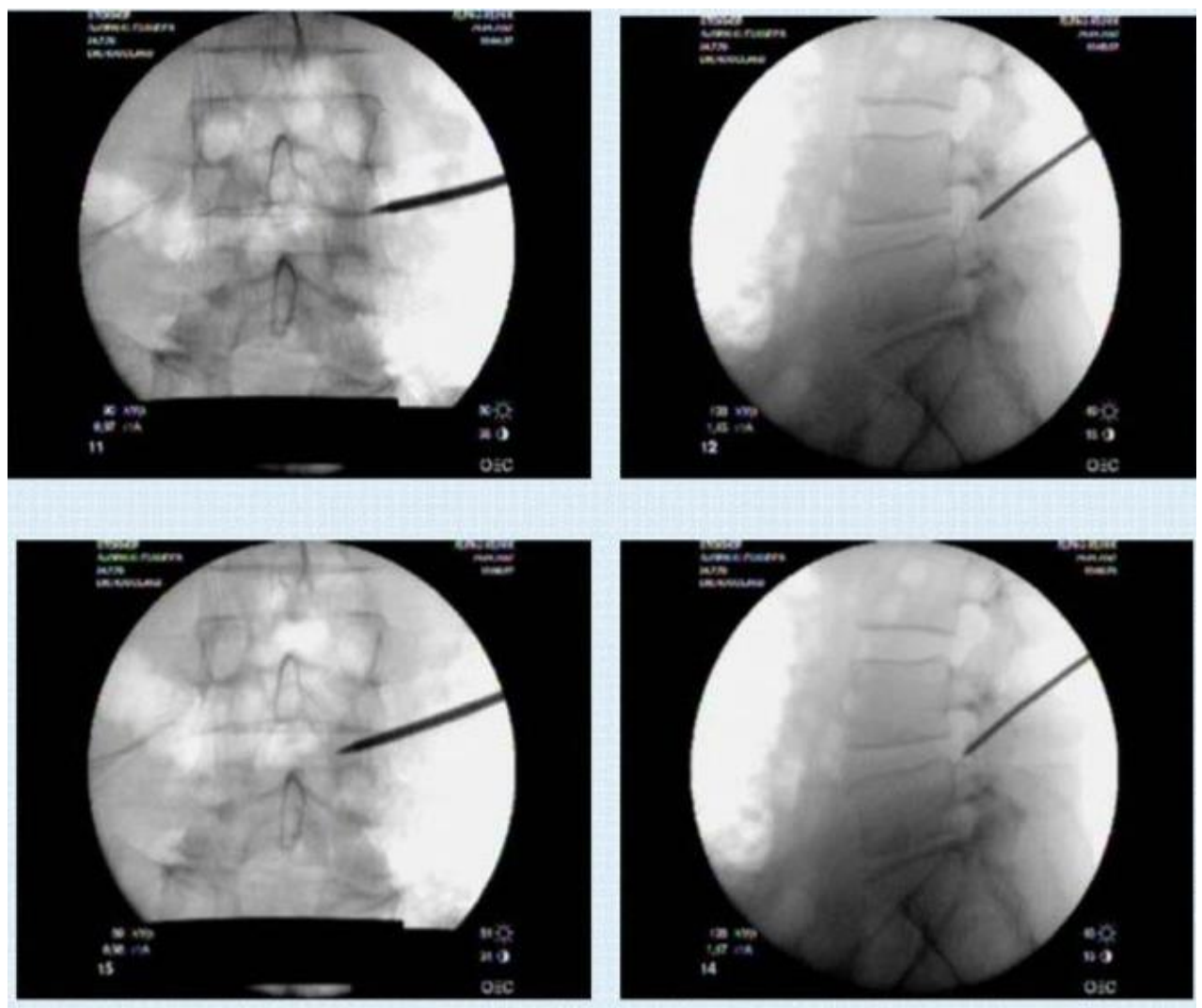

Fig. 3

Step 5: Dilatations by Safety Drills: Cannulated reamers are introduced sequentially upto 8 or $9 \mathrm{~mm}$ using the guide wire and drilled in anti-clockwise manner to prevent muscle damage. Care must be taken to avoid bending of the guidewire.

Step 6: Placing of the Working Cannula: The $7 \mathrm{~mm}$ conical rod is replaced by a working channel introduced at the site with its tip aiming at the posterior longitudinal ligament in order to avoid nerve root entrapment. The endoscope with a saline $9 \%$ pump connected to the rinsing channel is ready for use.

Step 7: Decompressing the Nerve: Next, in order to remove all loose fragments a rongeur will be introduced. Increasing pump pressure or occasionally a bipolar can be useful to control bleeding. On the screen the posterior longitudinal ligament will be found in the lower part \& the facet joint will be seen in the upper part. The nerve root is identified behind the facet joint. The disk fragments are recognized by their yellow color, which are then grasped by the rongeur and slowly removed. If the fragments are too large to pass through the working channel, the fragment and endoscopy should be removed simultaneously. Radicular pain sensation will be felt by the patient, when fragments around the nerve roots are removed, especially when a foraminal stenosis is present. Therefore, slow gradual removal is advocated. If the nerve shows pulsations with the heart rate and the amount of removed disk

materials is quivalent to the herniated disc on MRI, the procedure is considered to be successful.

When the nerve root is not identifiable, pulsation of the epidural space along with the MRI-matched removal of disk herniation will be enough for sufficient decompression.

\section{Post-op protocol}

Patients were discharged 2-3 hours post surgery and were asked to follow -up for suture removal. No corset was prescribed.

\section{Observation and Results}

In our study 13 patients were male while 7 were female.

Most common presenting complaint was that of radicular pain in lower limb.

Average age of involvement was 35-40 years.

$65 \%$ of patients with disc prolapse 's occupation involved heavy weight lifting.

Amongst them the average Preoperative VAS score was 8.8 , which at the end of six weeks following surgery was decreased to 3.3.

The average hospital stay was about 1.2 days.

Also according to Macnabs criteria $80 \%$ of the individuals showed excellent and good results.

Out of the 20 patients who underwent Transforaminal lumbar discectomy, 1 patient showed no improvement in symptoms and subsequently required open discectomy. 
Also, one of the patients suffered from temporary which recovered subsequently in a few hours. neurological worsening due to excessive lignocaine,

Table 1

\begin{tabular}{|l|c|c|c|c|}
\hline S. No. & Name & Pre op vas & Post Op vas & Post op Macnab \\
\hline 1 & Male & 4.3 & 4.3 & Fair \\
\hline 2 & Male & 9 & 3.2 & Excellent \\
\hline 3 & Female & 9.5 & 4.8 & Excellent \\
\hline 4 & Male & 8.5 & 3.1 & Good \\
\hline 5 & Male & 9.1 & 2.9 & Excellent \\
\hline 6 & Female & 8.3 & 2.7 & Good \\
\hline 7 & Female & 7.5 & 4.6 & Fair \\
\hline 8 & Male & 9.4 & 4.9 & Excellent \\
\hline 9 & Female & 9.8 & 3 & Excellent \\
\hline 10 & Male & 8.1 & 3.6 & Good \\
\hline 11 & Male & 9.7 & 3.8 & Excellent \\
\hline 12 & Male & 8.6 & 4 & Good \\
\hline 13 & Female & 8.3 & 3.2 & Good \\
\hline 14 & male & 6.3 & 2.6 & Fair \\
\hline 15 & male & 7.8 & 4.1 & Fair \\
\hline 16 & Female & 8.9 & 2.1 & Good \\
\hline 17 & Female & 7 & 4.2 & Fair \\
\hline 18 & Male & 9 & 3.9 & Excellent \\
\hline 19 & Male & 3.9 & 4.1 & Poor \\
\hline 20 & Male & 8.6 & 4.6 & Good \\
\hline
\end{tabular}

\section{Chart Title}

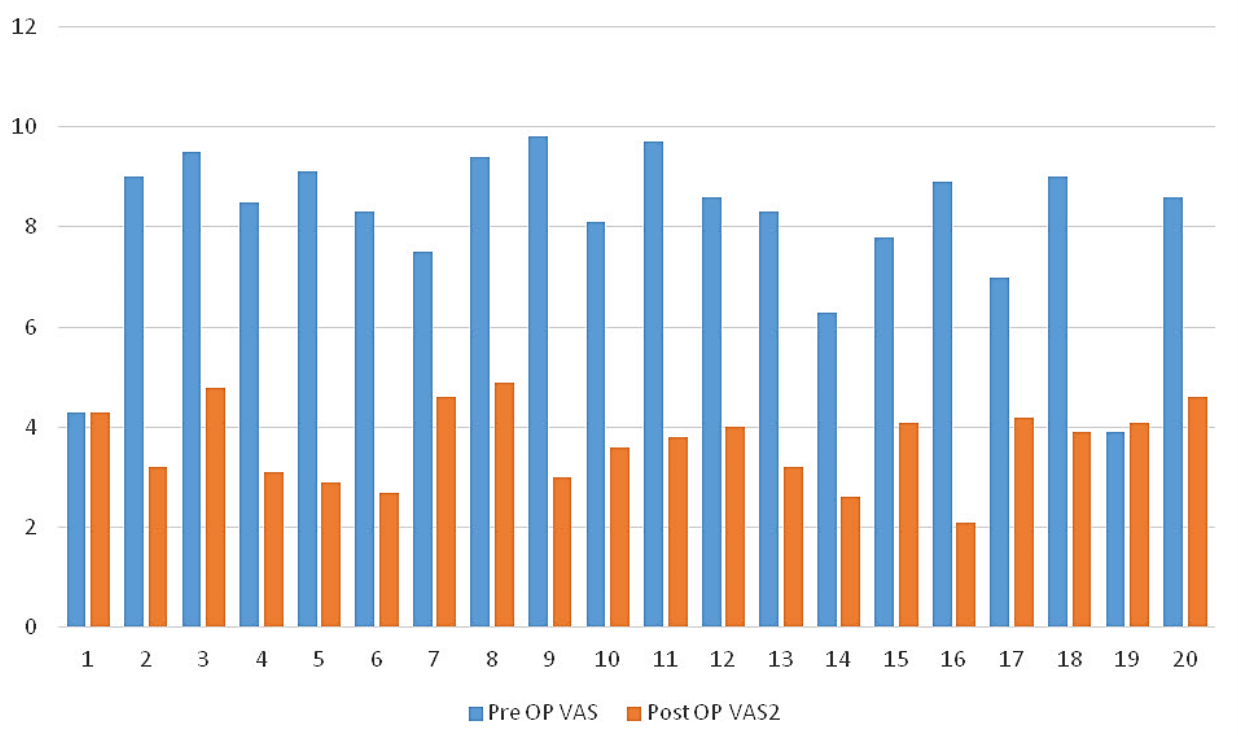

Fig. 4 


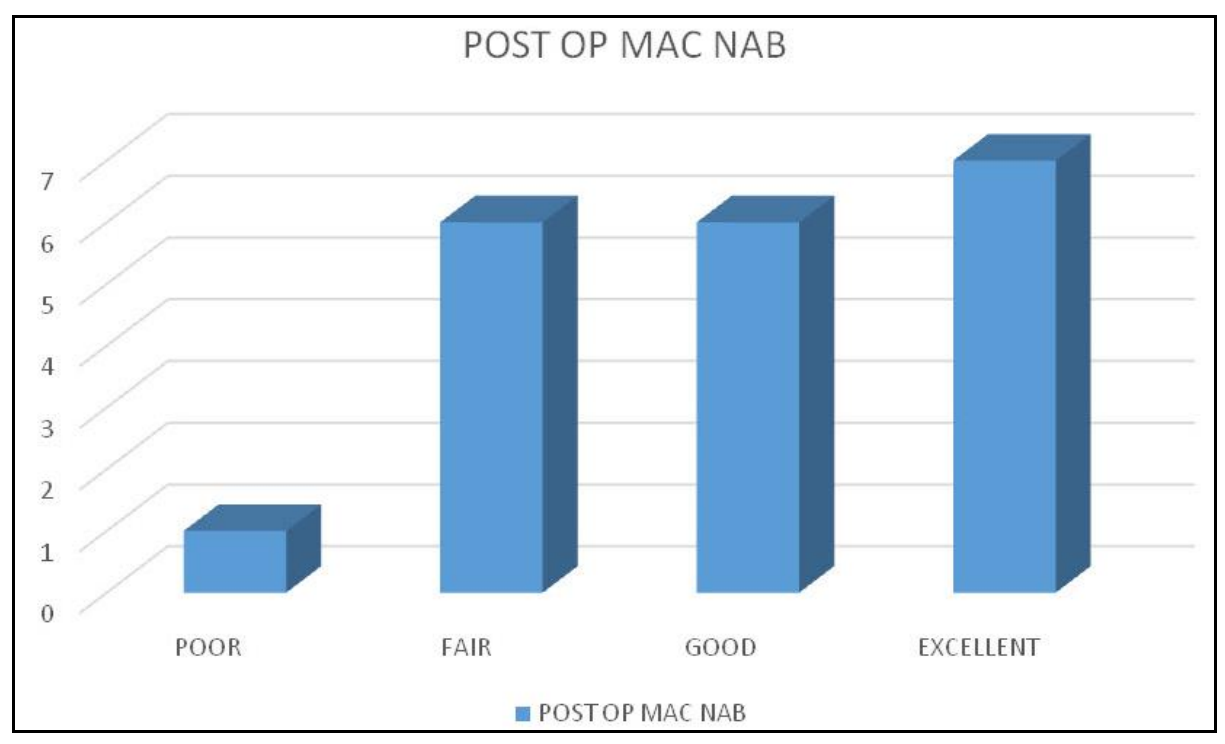

\section{Fig. 5}

\section{Case 1}

A case of 24 year old female presented with complaint of lower backache radiating to left lower limb. Postopertive improvement in radicular pain relief was that of $95 \%$.

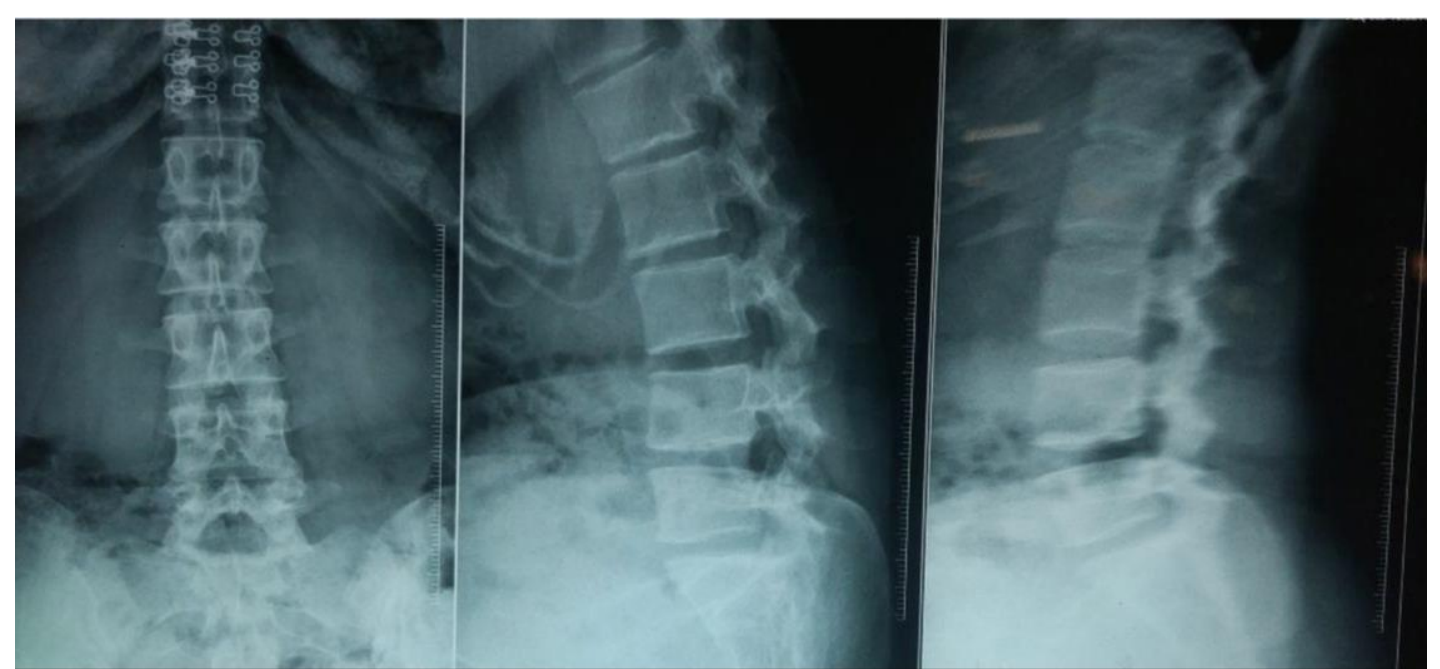

Fig. 6: Preoperative X-rays 


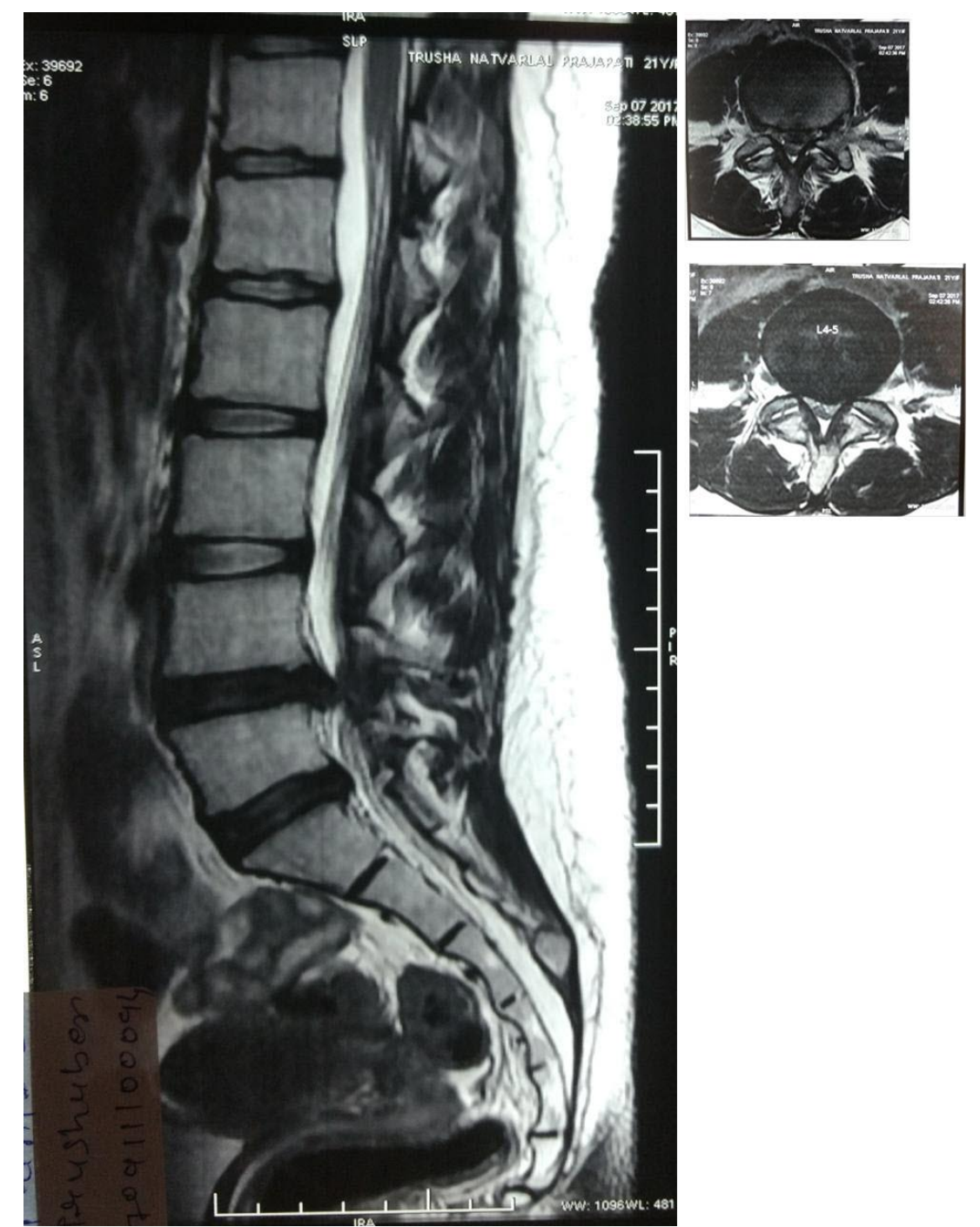

Fig.7: Preoperative MRI
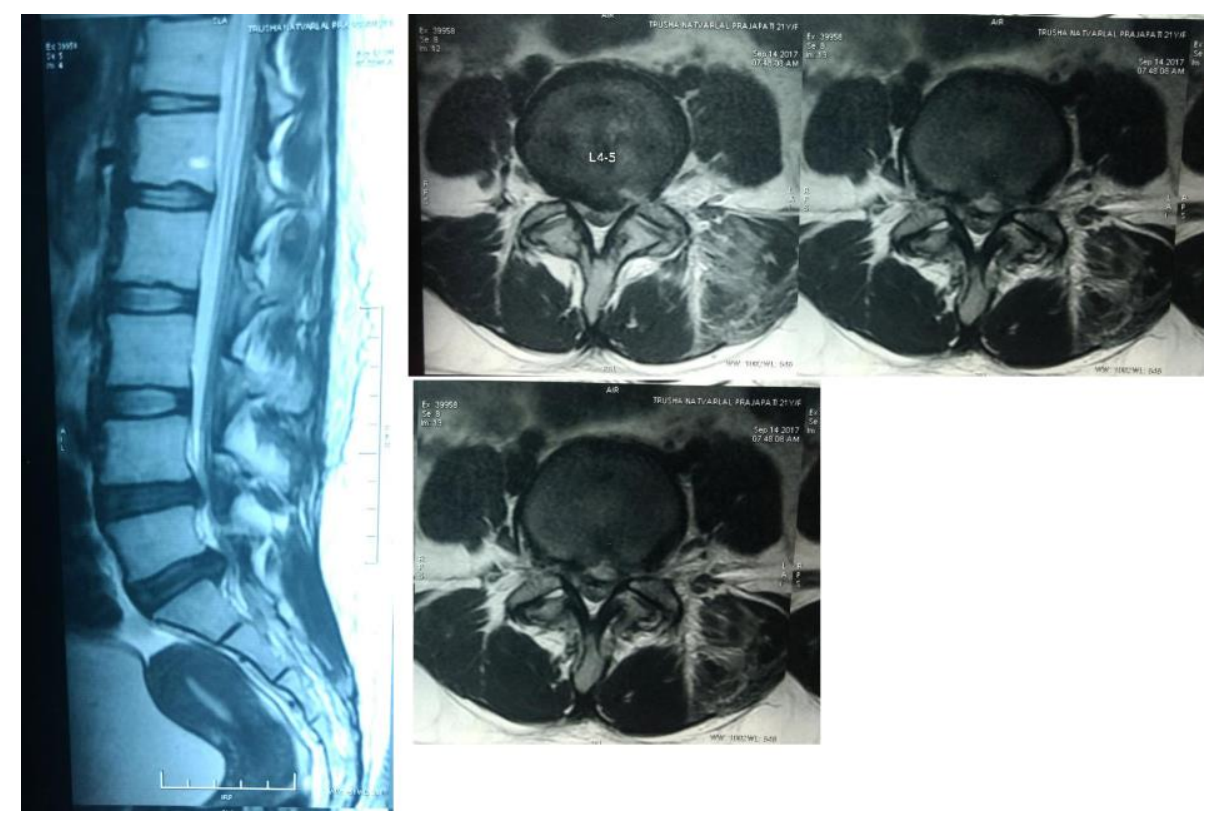

Fig. 8: Post-operative MRI

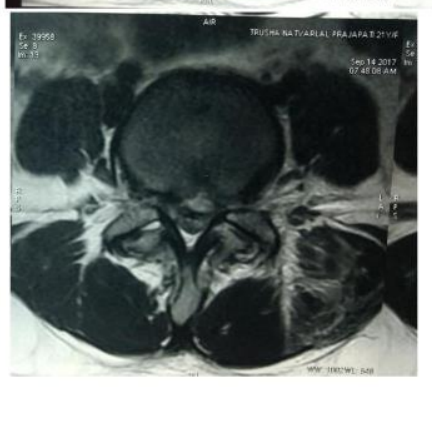




\section{Discussion}

As evident from the root it will cause radicular pain. Hence it acts as a conscious signal.

We had study and follow up of the patients transforaminal lumbar endoscopic discectomy could become the gold standard in future.

It is the procedure where patient is operated under local anaesthesia hence while during the procedure when probe touches

post-operative MRI done of all patients in which we found that inspite of not much radiological significance in post-operative, significant relief in radiculopathy was found $(>90 \%)$. This may be due to transforaminal decompression secondary to facet reaming. Concentric rings of annular disc and taut ligamentum flavum help push disc to area of decreased pressure. Hence this may too help in relieving canal compression.

Since we don't disturb the facetal joints the chances of spinal instability are minimum. ${ }^{5}$

This procedure has high patient satisfaction rate as there is significant improvement in quality of lives. No or minimal scar, lesser hospital stay and catching up early with day to day activities are its key benefits.

According to Yeung et al. ${ }^{9}$ The mean VAS for leg pain improved from $7.86 \pm 1.28$ preoperatively to $2.54 \pm 1.51$ at 6 weeks postoperatively and $1.85 \pm 1.07$ at 1 year postoperatively. Excellent or good global outcomes were obtained in $84.6 \%$, and the rate of symptomatic improvement was $92.3 \% .^{9}$

Yeung and Tsou (2002) described results of posterolateral disc excision in 307 patients with minimal followup period of 1 year. They reported satisfactory result rate in $89.7 \%$ and poor results in 10.3 patients. The complications were deep infection in two, thrombophlebitis in two, dysesthesia in six, and dural tear in one patient.

Chae et al. $(2009)^{10}$ reported $94.77 \%$ satisfactory results with percutaneous endoscopic discectomy in 153 patients with difficult, noncontained lumbar disc herniations.

Being an endoscopic procedure the amount of muscle trauma is significantly reduced. Dorsal column muscles amount for proprioception and segmental mobility. Even in the smallest incision it can lead to fibrosis, resulting in loss of their function. Hence preserving these muscles is one of the biggest advantage.

Since the procedure is performed under local anaesthesia and is a day care surgery, it helps to meet the patient load in a government setup like ours.

It is the only approach where disc can be approached without potentially destabilising the spine.

Trans canal approach not only makes the spine unstable but also there are higher chances of recurrent herniation. Removal of the disc by trans canal approach will need a cruciate incision with annulotomy knife and by doing this there will be further weakening of the tear, increasing the chances of recurrence.

Transforaminal approach prevents excessive removal of the ligamentum flavum which is an important barrier between dura and muscles.

Technically transforaminal procedure is difficult but once the expertise is achieved superior results can be achieved.

As with all procedures transforaminal endoscopic lumbar discectomy has its disadvantages too. All herniation are not accessible through this approach especially extrarticular disc herniation at L5-S1 level. Pathologies like facet hypertrophy, spondylosis, severe stenosis are barriers to this technique.

Moreover there are chances of root injury, hence dysthesias $^{6,7}$ are quite common after this approach. Usually these dysthesias are transient in nature. Other similar study done by Peng et al showed complication rate was $2.6 \%$ which included dural tear, vascular injury, dysthesia. ${ }^{8}$

\section{Conclusion}

Transforaminal Lumbar discectomy being an endoscopic procedure which gives equal or better results as compared to that of Open Discectomy. It's still a novel technique for most of the government tertiary care centres with heavy load of patients but lack of advanced tools and technology. In spite of having a steep learning curve and high one time cost of instruments, it could become gold standard as it relieves symptoms immediately reducing surgical and anaesthetic complications like infection, dural tear. Since it is a day care surgery, patients can resume their jobs sooner resulting in better patient satisfaction and compliance and rapid turnover of patients in hospitals.

\section{References}

1. http://maxmorespine.com

2. Kambin P, Brager M. Percutaneous Posterolateral Discectomy. Anatomy and Mechanism. Clin Orthop. 1987;223:145-54.

3. Kambin P, Gellman H. Percutaneous Lateral Discectomy of the Lumbar Spine: A Preliminary Report. Clin Orthop. 1983;174:127-32.

4. Ruetten S, Komp M, Godolias G. An extreme lateral access for the surgery of lumbar disc herniations inside the spinal canal using the full-endoscopic uniportal transforaminal approach-technique and prospective results of 463 patients. Spine. 2005;30:2570-8. 10.1097/01.brs.0000186327.21435.cc.

5. Schaffer JL, Kambin P. Percutaneous posterolateral lumbar discectomy and decompression with a $6.9 \mathrm{~mm}$ cannula: Analysis of operative failures and complications.

6. Blankstein A, Rubinstein E, Ezra E, Lokiec F, Caspi I, Horoszowski H. Disc Space Infection and Vertebral Osteomyelitis as a complication of Percutaneous Lateral Discectomy.

7. Kambin P, Casey K, O'Brien E, Zhou L. Transforaminal arthroscopic decompression of lateral recess stenosis. $J$ Neurosurg. 1996;84(3):462-7. 
8. Chan WB Peng. Percutaneous endoscopic lumbar discectomy: clinical and quality of life outcomes. $J$ Orthop Surg Res. 2009;4:20.

9. Yeung AT, Tsou PM. Posterolateral endoscopic excision for lumbar disc herniation: Surgical technique, outcome, and complications in 307 consecutive cases. Spine (Phila Pa 1976). 2002;27:722-31.

http://www.sciencedirect.com/science/article/pii/S030384 6716301871

10. Chae KH, Ju CI, Lee SM, Kim BW, Kim SY, Kim HS Strategies for noncontained lumbar disc herniation by an endoscopic approach: Transforaminal suprapedicular approach, semi-rigid flexible curved probe, and 3dimensional reconstruction CT with discogram. J Korean Neurosurg Soc. 2009;46:312-6.

How to cite this article: Modi JPV, Shah BB, Patel HR, Mehta MS, Patel DV. Percutaneous transforaminal lumbar endoscopic discectomy: An appropriate outpatient procedure for lumbar disc pathologies in a high output tertiary care centre. Indian J Orthop Surg. 2018;4(3):256263. 